\title{
M/D/1 Feedback Queueing Models with Retention of Reneged Customers
}

\author{
Dr. S. K. Tiwari ${ }^{1}$, Dr. V. K. Gupta ${ }^{2}$, Tabi Nandan Joshi ${ }^{3}$ \\ ${ }^{1}$ School of Studies in Mathematics, Vikram University, Ujjain, India \\ ${ }^{2}$ Govt. Madhav Scinnce Colleges, Vikram University, Ujjain, India \\ ${ }^{3}$ School of Studies in Mathematics, Vikram University, Ujjain, India
}

\begin{abstract}
Every organization is facing the problem of customer impatience. Customer retention is the key issue in this context. Organizations are applying strategies to sustain their businesses. An impatient customer (due to reneging) may be convinced to stay in service system for his service by utilizing certain convincing mechanisms. Such customers are termed as retained customers. Queueing with feedback represents customer dissatisfaction because of unsuitable quality of service. In case of feedback, after getting partial or incomplete service, customer retries for service. Customer Retention is incorporated in a single-server Markovian feedback queueing model. The steady-state solution of the models is derived. Some useful measures of performance are derived. A particular case of the model is discussed.
\end{abstract}

Keywords: Customer retention, Feedback, Reneging; Steady-State Solution.

\section{Introduction}

A queue, or a waiting line, involves arriving items that wait to be served at the facility which provides the service they seek. Queuing theory is concerned with the statistical description of the behavior of the queues with result, e.g., the probability distribution of the number in the queue from which the mean and variance of queue length and the probability distribution of waiting time for a customer, or the distribution of a server's busy period can be found. In this paper we have discussed about a steady state solution of the ordered queuing problem with reneging.

A customer may enter the queue, but after a time lose patience and decide to leave. In this case the customer is said to have reneged. A unit reneges (i.e., becomes impatient and leaves without having been served) after joining the queue if it is decided that the wait will be longer than can be tolerated. Here the waiting line is of Poisson balking probability which depend not only on the number of customers in the system, but also on the rate of service in the system. A queuing situation with the following characteristics has been considered. A customer receives the service immediately, when the system is empty. But a joining customer that has to wait for service due to impatience may leave i.e., the customer may renege. Service is performed on the customer at the head of the line. One service has commenced on a customer, it remains until the completion of service.

Barrer [7] has studied the problem of a unit leaving a queue after having waited longer than an acceptable time. O. Brien [9] has also found the solution of some queuing problem. Miller [20] and Konigsberg [8] have also studied about balk queue and queuing with special service. In this paper we have attempted to find out a steady state solution of queue, when the Poisson probabilities depend not only on the number of the customers in the system.
Customers are the backbone of any business, because without customers there will be no reason for a business to operate. Customer impatience leads to loss of potential customers. It has become a highly challenging problem in the current era of cut-throat competition. Queueing with customer impatience has special significance for the business world as it has a very negative effect on the revenue generation of a firm. Therefore, the concept of customer retention assumes a tremendous importance for the business management. Customer retention is the key issue in the organizations facing the problem of customer impatience. Firms are employing a number of customer retention strategies to maintain their businesses. An impatient customer (due to reneging) may be convinced to stay in service system for his service by utilizing certain persuasive mechanisms. Such customers are termed as retained customers.

When a customer gets impatient, he may leave the queue with some probability, say $p_{2}$ and may remain in the queue for service with some complementary probability $q_{2}$ $\left(=1-p_{2}\right)$. Recently, Kumar and Sharma [14] study the retention of reneged customers in an $\mathrm{M} / \mathrm{M} / 1 / \mathrm{N}$ queuing model and perform sensitivity analysis of the model. Kumar and Sharma [15] study $\mathrm{M} / \mathrm{M} / 1 / \mathrm{N}$ queuing system with retention of reneged customers and balking. They extend the work of Kumar and Sharma [14] by taking balking aspects in their model to study the effect of probability of retaining the reneged customers on expected system size. They perform the sensitivity analysis of the model. We assume that after the completion of service, each customer may rejoin the system as a feedback customer for receiving another regular service with probability $\mathrm{p}_{1}$ and may not join with complementary probability $1-\mathrm{p}_{1}$.

Sharma and Kumar [21] study single-server finite capacity, Markovian queue with feedback and retention of reneged customers. They perform steady-state analysis of the model. 


\section{International Journal of Science and Research (IJSR) \\ ISSN (Online): 2319-7064 \\ Index Copernicus Value (2013): 6.14 | Impact Factor (2014): 5.611}

Sharma and Kumar [22] further study $M / M / 1 / N$ feedback queuing model with balking and retention of reneged customers in the same year. They obtain steady-state solution of the model. They derive important performance measures of the model. Some queueing models are derived as special cases of the model. This paper discussed the queueing model for deterministic service time. Some useful measures of performances are derived. Some queuing models are obtained as particular cases of the model. literature survey is also presented. Here, also present the steady-state analysis of a single-server Markovian feedback queuing system with retention of reneged customers. M/D/1 queuing model with retention of reneged customers considered.

\section{Literature Survey}

The earlier work on feedback is found in Takacs [23]. He studies queue with feedback to determine the stationary process for the queue size and the first two moments of the distribution function of the total time spent in the system by a customer. Davignon and Disney [6] study single server queues with state dependent feedback. Santhakumaran and Thangaraj [20] consider a single server feedback queue with impatient and feedback customers. They study $\mathrm{M} / \mathrm{M} / 1$ queueing model for queue length at arrival and obtain result for stationary distribution, mean and variance of queue length. Thangaraj and Vanitha [24] obtain transient solution of $\mathrm{M} / \mathrm{M} / 1$ feedback queue with catastrophes using continued fractions. The steady-state solution, moments under steady state and busy period analysis are calculated. Ayyappan [2] study $\mathrm{M} / \mathrm{M} / 1$ retrial queueing system with loss and feedback under non-pre-emptive priority service by matrix geometric method. Customer retention in a single-server, finite capacity, Markovian queueing model is studied by Kumar and Sharma [14], the related work on customer retention and its application is in [16], [17].

The concept of customer impatience appears in queueing theory in the work of Haight [11]. Haight [12] studies queuing with reneging. Ancker and Gafarian [1] study $\mathrm{M} / \mathrm{M} / 1 / \mathrm{N}$ queuing system with balking and reneging and derive its steady-state solution. Al-seedy et al. [3] study $\mathrm{M} / \mathrm{M} / \mathrm{c}$ queue with balking and reneging and derived its transient solution by using the probability generating function technique and the properties of Bessel function. Choudhury and Medhi [4] study customer impatience in multi-server queues. They consider both balking and reneging as functions of system state by taking into consideration the situations where the customer is aware of its position in the system. Kapodistria [13] study a single server Markovian queue with impatient customers and consider the situations where customers abandon the system simultaneously. He considers two abandonment scenarios. In the first one, all present customers become impatient and performed synchronized abandonments, while in the second scenario; the customer in service is excluded from the abandonment procedure. He extends this analysis to the $\mathrm{M} / \mathrm{M} / \mathrm{c}$ queue under the second abandonment scenario also.

In this paper, infinite capacity, single-server deterministic service feedback queueing model with customer retention is studied. The steady-state analysis is performed. The steady state probabilities are obtained iteratively in case of reneging and retention of reneged customers. The performance measures are derived and some queuing models are discussed as particular cases of the model.

\section{M/D/1 Feedback Queuing Model with Retention of Reneged Customers}

In case of feedback, after the completion of service, each customer may rejoin the system as a feedback customer for receiving another regular service with probability $\mathrm{p}_{1}$ and may not join with complementary probability $1-\mathrm{p}_{1}$. We consider an $\mathrm{M} / \mathrm{D} / 1$ feedback queuing model with reneging. The reneging times are assumed to exponentially distributed with parameter $\xi$. It is visualized that a reneged customer may be convinced by applying certain convincing method to stay in the system for his service. Thus, there is a probability say, $q_{2}$ that a reneged customer may be retained in the system and may not be retained with some complementary probability say, $p_{2}=\left(1-q_{2}\right)$.

The differential-difference equations of the model are:

$$
\frac{d}{d t} P_{0}(t)=-\lambda P_{0}(t)+\mu q_{1} P_{1}(t)
$$

Where $P_{n}(t)$ is the probability of $\mathrm{n}$ in the system at time ' $\mathrm{t}$ '. [11]

Here, we use deterministic service time model. The approach we use is similar to to be found in saaty [19] and which is essentially originally due to Crommelin [5]. In the $\mathrm{M} / \mathrm{D} / 1$ queueing model the arrival rate is $\lambda$ and the constant service time (say $b=1 / \mu)$.

Now we rescale our parameter as $\lambda=\lambda / \mathbf{b}$ and $\boldsymbol{\mu}=\mathbf{1}[10]$ so that the traffic intensity ' $\rho$ ' $\left(=\frac{\lambda}{\theta}\right)$ remains unaffected.

The differential-difference equation of the model according to above condition becomes:

$$
\begin{gathered}
\frac{d}{d t} P_{0}(t)=-\frac{\lambda}{b} P_{0}(t)+q_{1} P_{1}(t) \\
\frac{d}{d t} P_{n}(t)=-\left[\frac{\lambda}{b}+q_{1}+(n-1) \xi p_{2}\right] P_{n}(t)+ \\
\left(q_{1}+n \xi p_{2}\right) P_{n+1}(t)+\frac{\lambda}{b} P_{n-1}(t) \quad \mathrm{n} \geq 1 \ldots \ldots
\end{gathered}
$$

In steady state, $\lim _{t \rightarrow \infty} P_{n}=P_{n}$ and therefore $\frac{d}{d t} P_{n}(t)=$ 0 as $t \rightarrow \infty$ and hence the equation (1) and (2) gives the difference equations as

$$
\begin{gathered}
0=-\frac{\lambda}{b} P_{0}(t)+q_{1} P_{1}(t) \\
0=-\left[\frac{\lambda}{b}+\mathrm{q}_{1}+(\mathrm{n}-1) \xi \mathrm{p}_{2}\right] \mathrm{P}_{\mathrm{n}}(\mathrm{t})+\left(\mathrm{q}_{1}+\mathrm{n} \xi \mathrm{p}_{2}\right) \mathrm{P}_{\mathrm{n}+1}(\mathrm{t}) \\
+\frac{\lambda}{\mathrm{b}} \mathrm{P}_{\mathrm{n}-1}(\mathrm{t})
\end{gathered}
$$

$\mathrm{n} \geq 1$ 


\section{International Journal of Science and Research (IJSR) \\ ISSN (Online): 2319-7064}

Index Copernicus Value (2013): 6.14 | Impact Factor (2014): 5.611

On solving iteratively, the steady state probabilities of system size are given by

$$
\begin{aligned}
& P_{n}=\prod_{k=1}^{\infty}\left(\frac{\frac{\lambda}{b}}{q_{1}+(k-1) \xi p_{2}}\right) P_{0} ; \quad \mathrm{n} \geq 1 \\
& \text { With } \quad P_{0}=\frac{1}{\left(1+\sum_{n=1}^{\infty} \prod_{k=1}^{n}\left(\frac{\frac{\lambda}{b}}{q_{1}+(k-1) \xi p_{2}}\right)\right)}
\end{aligned}
$$

The steady state probabilities exist if

$$
\left(1+\sum_{n=1}^{\infty} \prod_{k=1}^{n}\left(\frac{\frac{\lambda}{b}}{q_{1}+(k-1) \xi p_{2}}\right)\right)<\infty
$$

\section{Measures of Performance}

In this section, some important measures of performance are derived. These can be used to study the performance of the queuing system under consideration.

Measures of Performance:

4.1 The Expected System size, $\mathbf{L}_{\mathbf{s}}$

$$
\begin{gathered}
L_{s}=\sum_{n=0}^{\infty} n P_{n} \\
L_{s}=\sum_{n=1}^{\infty} n\left(\prod_{k=1}^{\infty} \frac{\frac{\lambda}{b}}{q_{1}+(k-1) \xi p_{2}}\right) P_{0}
\end{gathered}
$$

4.2 The Expected Queue Length $\mathbf{L}_{\mathbf{q}}$

$$
\begin{gathered}
L_{q}=\sum_{n=0}^{\infty} n P_{n}-\frac{\lambda}{b q_{1}} \\
L_{q}=\sum_{n=1}^{\infty} n\left(\prod_{k=1}^{\infty} \frac{\frac{\lambda}{b}}{q_{1}+(k-1) \xi p_{2}}\right) P_{0}-\frac{\lambda}{b q_{1}}
\end{gathered}
$$

4.3 The Expected waiting time $\mathbf{W}_{\mathbf{s}}$

$$
W_{s}=\frac{b}{\lambda} \sum_{n=1}^{\infty} n\left(\prod_{k=1}^{\infty} \frac{\frac{\lambda}{b}}{q_{1}+(k-1) \xi p_{2}}\right) P_{0}
$$

4.4 The Expected waiting time in the queue $\mathbf{W}_{\mathbf{q}}$

$$
W_{q}=\left[\frac{b}{\lambda} \sum_{n=1}^{\infty} n\left(\prod_{k=1}^{\infty} \frac{\frac{\lambda}{b}}{q_{1}+(k-1) \xi p_{2}}\right) P_{0}-\frac{1}{q_{1}}\right]
$$

4.5 The Expected number of customers served, $\left(\mathbf{E}_{\mathbf{c s}}\right)$ The expected number of customer served is given by

$$
\begin{gathered}
E_{c s}=q_{1} \sum_{n=1}^{\infty} P_{n} \\
E_{c S}=q_{1} \sum_{n=1}^{\infty}\left(\prod_{k=1}^{\infty} \frac{\frac{\lambda}{b}}{q_{1}+(k-1) \xi p_{2}}\right) P_{0}
\end{gathered}
$$

4.6 Rate of Abandonment, $\mathbf{R}_{\text {aband }}$

$$
R_{\text {aband }}=\frac{\lambda}{b} \sum_{n=0}^{\infty} P_{n}-E_{c s}
$$

$$
R_{\text {aband }}=\frac{\lambda}{b}-q_{1} \sum_{n=1}^{\infty}\left(\prod_{k=1}^{\infty} \frac{\frac{\lambda}{b}}{q_{1}+(k-1) \xi p_{2}}\right) P_{0}
$$

4.7 Expected number of waiting customers actually waits, $\mathbf{E}_{\mathrm{cw}}$

$$
E_{c w}=\frac{E_{c w}=\frac{\sum_{n=2}^{\infty}(n-1) P_{n}}{\sum_{n=2}^{\infty} P_{n}}(n-1)\left(\prod_{k=1}^{\infty} \frac{\frac{\lambda}{b}}{q_{1}+(k-1) \xi p_{2}}\right) P_{0}}{\sum_{n=2}^{\infty}\left(\prod_{k=1}^{\infty} \frac{\lambda}{q_{1}+(k-1) \xi p_{2}}\right) P_{0}}
$$

Where $\mathrm{P}_{0}$ is given in eq.(6).

\subsection{Particular Cases of the Model}

In this section, we derive some important Markovian queuing models from the $\mathrm{M} / \mathrm{M} / 1$ feedback queuing model with retention of reneged customers.

In the absence of retention of reneged customer. When the probability of retention of Reneged customer is zero. i.e., $\mathrm{q}_{2}=0$

$$
\begin{array}{ll}
P_{n}=\prod_{k=1}^{\infty} \frac{\frac{\lambda}{b}}{q_{1}+(k-1) \xi} P_{0} ; & \mathrm{n} \geq 1 \\
\text { With } \quad P_{0}=\frac{1}{\left(1+\sum_{n=1}^{\infty} \prod_{k=1}^{\infty} \frac{\frac{\lambda}{b}}{q_{1}+(k-1) \xi}\right)} &
\end{array}
$$

When the capacity of the system is finite

$$
\begin{aligned}
& P_{n}=\prod_{k=1}^{n} \frac{\frac{\lambda}{b}}{q_{1}+(k-1) \xi p_{2}} P_{0} ; \quad 1 \leq \mathrm{n} \leq \mathrm{N} \\
& \text { With } \quad P_{0}=\frac{1}{\left(1+\sum_{n=1}^{\infty} \prod_{k=1}^{\infty} \frac{\frac{\lambda}{b}}{q_{1}+(k-1) \xi p_{2}}\right)}
\end{aligned}
$$

When the Probability of Retention of Reneged Customer (i.e. for $\mathrm{q}_{2}=0$ ) In the absence of retention of reneged customer (i.e. for $\mathrm{q}_{2}=0$ ), our model reduces to an $M / D / 1$ feedback queuing model with reneging. When the Capacity of the System is Finite When the capacity of the system is taken as finite say, $\mathrm{N}$, the resulting model is an $\mathrm{M} / \mathrm{D} / 1 / \mathrm{N}$ feedback queuing model with retention of reneged customers.

\section{Conclusions}

In this paper, we have studied customer retention in an $\mathrm{M} / \mathrm{D} / 1$ feedback queuing model with reneging and in an $\mathrm{M} / \mathrm{D} / 1$ feedback queuing model with reneging and balking. The steady-state solution is obtained for the queuing model. Some important measures of performance are derived. Some important queuing models are obtained as particular cases of the model.

\section{References}

[1] Ancker Jr., C. J. and Gafarian, A. V., Some Queuing Problems with Balking and Reneging. I, Operations Research, vol. 11, no. 1, pp. 88-100, 1963.

[2] Ayyapan, G., Muthu Ganapathi Subramanian, A. and Sekar, G., M/M/1 Retrial Queueing System with Loss 


\section{International Journal of Science and Research (IJSR) \\ ISSN (Online): 2319-7064 \\ Index Copernicus Value (2013): 6.14 | Impact Factor (2014): 5.611}

and Feedback under Non-pre-emptive Priority Service by Matrix Geometric Method, Applied Mathematical Sciences, vol. 4, no. 48, pp. 2379-2389, 2010.

[3] Al-Seedy, R.O., El-sherbiny, A.A., El-Shehawy, S.A, and Ammar, S.I., Transient Solution of the M/M/c queue with balking and reneging, Computer and Mathematics with Applications, vol. 57, no. 8, pp. 1280-1285, 2009.

[4] Choudhury, A., and Medhi, P., Balking and reneging in multiserver Markovian queuing systems, International Journal of Mathematics in Operational Research, vol. 3, no. 4, 377-394, 2011.

[5] Crommelin, C. D. 1932. Delay Probability formulae when the holding times are constant. P. O. Electrical Engineering Journal 25, 41-50.

[6] D' Avignon, G.R. and Disney, R.L., Single Server Queue with State Dependent Feedback, INFOR, vol. 14, pp. 71-85, 1976.

[7] D.Y.Barrer, Queueing with impatient customers and indifferent clerks, Operation Research,Vol.5,No.5.1957.

[8] E.Koenigsberg,Queueing with special service, Operation Research,Vol.4,213-220, 1956.

[9] G.G.O,Brien, The solution of some queuing problems, J.Soc.Ind.Appl.Math., Vol.2,133-142,1954.

[10] Gross, D. Shortle, J. Thompson, J. and Harris, C., Fundamentals of Queueing Theory, Forth edition, Wiley, Poisson Input, Constant Service. pp- 294. 2013.

[11] Haight, F. A., Queuing with balking, I, Biometrika, vol. 44, pp. 360-369, 1957.

[12] Haight, F. A., Queueing with Reneging, Mettrika vol. 2, pp. 186-197, 1959.

[13] Kapodistria, S., The M/M/1 queue with synchronized abandonments, Queuing Systems, vol. 68,pp. 79-109, 2011.

[14] Kumar, R. and Sharma, S.K., M/M/1/N queuing system with retention of reneged customers, Pakistan Journal of Statistics and Operation Research, vol. 8, no. 4, pp. 859866, 2012.

[15] Kumar, R. and Sharma, S.K., M/M/1 queueing model with retention of reneged customers and balking, American Journal of Operational Research, vol. 2, 3(2A) no. 1, pp. 1-6, 2013.

[16] Kumar, R. and Sharma, S.K., Managing congestion and revenue generation in supply chains facing customer impatience, Inventi Impact: Supply Chain \& Logistics, vol. 2012, pp. 13-17, 2012.

[17] Kumar, R. and Sharma, S.K., Formulation of Product Replacement Policies for Perishable Inventory Systems using Queuing Theoretical Approach, American Journal of Operational Research, vol. 2, no. 4, pp. 27-30, 2012.

[18] R.G.Miller, A contribution to the theory of balk queues, J. Roy Statist. Soc., Vol.21, No.2, 320-337, 1959.

[19] Saaty, T. L. 1961, Elements of Queueong Theory with Applications McGraw Hill, New York.

[20] Santhakumaran, A. and Thangaraj, V., A Single Server Queue with Impatient and Feedback Customers, Information and Management Science, vol. 11, no. 3, pp. 71-79, 2000.

[21] Sharma S.K. and Kumar R., A Markovian feedback Queue with Retention of Reneged Customers, AMOAdvanced Modelling and Optimization, vol. 14, no. 3, pp. 673-679, 2012.
[22] Sharma S.K. and Kumar R., A Markovian feedback Queue with Retention of Reneged Customers and Balking, AMO-Advanced Modelling and Optimization, vol. 14, no. 3, pp. 681-688, 2012.

[23] Takacs, L., A Single Server Queue with Feedback, The Bell System Tech. Journal, vol. 42, pp. 134-149, 1963.

[24] Thangaraj, V. and Vanitha, S., On the Analysis of M/M/1 Feedback Queue with Catastrophes using Continued Fractions, International Journal of Pure and Applied Mathematics, vol. 53, no. 1, pp. 131-151, 2009. 